\title{
Hepatic transcriptome profile of sheep (Ovis aries) in response to overgrazing: novel genes and pathways revealed
}

\author{
Weibo Ren ${ }^{1}$, Warwick Badgery², Yong Ding ${ }^{1}$, Huiqin Guo ${ }^{3}$, Yang Gao ${ }^{4}$ and Jize Zhang ${ }^{1 *}$ (D)
}

\begin{abstract}
Background: Overgrazing is a major factor that causes steppe degradation in Inner Mongolian, resulting in extensive ecosystem damage. Scarcity of grass means sheep are smaller and therefore mutton and cashmere production is greatly reduced, which has resulted in massive annual economic losses. Liver is the primary metabolic organ in mammals. It is also the key source of energy supply and detoxification of metabolites in animals, has a close relationship with animal growth. However, investigations on the responses of sheep induced by consequence of overgrazing, particularly those relating to liver-related molecular mechanisms and related metabolic pathways, remain elusive.

Results: The body weight daily gain of sheep, immune organ indices (liver and spleen), and serum parameters related to immune response, protein synthesis and energy supply (lgG, albumin, glucose and non-esterified fatty acid) were significantly lower in the overgrazing group. Other serum parameters including alanine aminotransferase, aspartate aminotransferase, alkaline phosphatase, total bilirubin, blood urea nitrogen and interleukin- 6 were significantly higher in the overgrazing group. For the RNA-Seq results, we identified approximately 50 differentially expressed genes, of which half of were up-regulated and the other half were down-regulated (overgrazing group versus light grazing group). Bioinformatics analysis identified two enriched KEGG pathways including peroxisome proliferator-activated receptor (PPAR) signaling pathway (related to lipolysis) and ECM-receptor interaction (related to liver injury and apoptosis). Additionally, several of the down-regulated genes were related to detoxification and immune response.

Conclusions: Overall, based on the high-throughput RNA sequencing profile integrated with the results of serum biochemical analyses, consequences of lower forage availability and quality under overgrazing condition induced altered expression levels of genes participating in energy metabolism (particularly lipid metabolism) and detoxification and immune responses, causing lipolysis and impaired health status, which might be key reasons for the reduced growth performance of sheep. This investigation provides a novel foundation for the development of sheep hepatic gene interactive networks that are a response to the degraded forage availability under overgrazing condition.
\end{abstract}

Keywords: Overgrazing, Liver, Transcriptome, RNA-Seq, Sheep

\section{Background}

In China, the steppes of Inner Mongolian are mainly utilized in mutton, milk and cashmere production [1] In recent decades, overgrazing has severely damaged this natural grassland, which threatens the normal morphology of forages (lower forage production and imbalanced

\footnotetext{
* Correspondence: jzz2006@126.com

${ }^{1}$ Key Laboratory of Forage Grass, Ministry of Agriculture, Institute of Grassland Research, Chinese Academy of Agricultural Sciences, Hohhot 010010, Inner Mongolia, China

Full list of author information is available at the end of the article
}

nutrients composition) and then reduces the individual animal growth performance [2-4]. Increases in stocking rate (SR) have induced grassland plants to accumulate volatile organic compounds as well as altered their morphology [5]. Multi-year investigations have shown that overgrazing significantly decreases body weight gain in sheep during grazing $[6,7]$.

The mammalian liver serves as the metabolic center and largely contribute to the in vivo metabolism of a wide range of nutrients, such as carbohydrates, proteins, and lipids. In addition, the liver also functions in the 
generation of immune and inflammatory responses, as well as in xenobiotics clearance $[8,9]$. Thus, because the liver is an important, metabolically active organ, hepatic response has been examined to explore the regulatory mechanisms of animal growth [10]. Previous studies have examined the impact of overgrazing on grassland productivity and animal behavior $[11,12]$. However, to date, little quantitative data are available on the growth-related hepatic responses of sheep due to consequences of overgrazing (especially lower forage availability and quality), which greatly interferes with defining an optimal grazing intensity (GI) and improving animal production.

Transcriptome analysis is widely applied to study comparative gene expression [13, 14]. The advent of nextgeneration sequencing technologies has improved and hastened expression profiling at the genome-level, providing extensive genetic information $[15,16]$. Numerous studies show that marked alterations occur in hepatic transcriptome profiles of ruminant animals due to changes in environmental factors or dietary composition, particularly novel genes and pathways related to nutrient metabolism (glucogenesis, fatty acid oxidation, amino acids metabolism), cell growth and transcriptional and translational regulation (DNA replication and transcription) $[17,18]$. Therefore, the goals of the present study were to perform transcriptome sequencing of sheep liver to detect differentially expressed genes (DEGs) in response to overgrazing triggered forage degradation, elucidating molecular mechanisms of lower animal growth performance.

\section{Results}

Effects of overgrazing on forage nutritional contents and sheep growth performance

In the present study, the overgrazing (OG) group exhibited higher crude protein $(\mathrm{CP})$ and acid detergent lignin (ADL) content compared to the light grazing (LG) group $(P<0.05)$. The gross energy and nitrogen free extract (NFE) levels of the OG group were significantly lower $(P<0.05)$ relative to the LG group (Additional file 1: Table S1). No significant differences of neutral detergent fiber (NDF) and acid detergent fiber (ADF) was observed in both groups (Additional file 1: Table S1). For the entire grazing experimental period ( 90 days), sheep under the OG condition had less daily weight gain (DWG) $(P<0.05)$ and lower carcass weight $(P<0.05$; Table 1$)$. Additionally, the indices of spleen and liver decreased significantly in the OG sheep $(P<0.05$; Table 1$)$.

\section{Effects of overgrazing on serum parameters of sheep}

Based on the results of serum biochemical indices, inflammatory responses and immune responses (Table 2), degraded forage availability and quality under OG
Table 1 The effects of overgrazing on sheep growth and immune organ indices

\begin{tabular}{lll}
\hline Item & Groups \\
\cline { 2 - 3 } & LG & OG \\
\hline DWG (g/d) & $156 \pm 36^{\mathrm{a}}$ & $133 \pm 24^{\mathrm{b}}$ \\
Carcass weight cold (kg) & $23.2 \pm 1.5^{\mathrm{a}}$ & $21.1 \pm 0.9^{\mathrm{b}}$ \\
Index of spleen (\%) & $0.46 \pm 0.04^{\mathrm{a}}$ & $0.32 \pm 0.07^{\mathrm{b}}$ \\
Index of liver (\%) & $3.38 \pm 0.14^{\mathrm{a}}$ & $2.95 \pm 0.08^{\mathrm{b}}$ \\
\hline
\end{tabular}

Values within a row with different superscript letters represent significant differences at $P<0.05$. Numbers are expressed as the means \pm SD. (DWG, $n=$ 12 for LG and $n=36$ for OG; indices of immune organs, $n=6$ )

1) Immune organ indices were computed as the ration of organ weight to body weight

DWG Daily weight gain, LG Light grazing, OG Overgrazing

condition significantly affected these parameters. Alanine aminotransferase (ALT), aspartate aminotransferase (AST) and alkaline phosphatase (ALP) activities, total bilirubin (TBIL), serum blood urea nitrogen (BUN) and interleukin-6 (IL-6) concentrations significantly increased in the OG group compared to the LG group $(P<0.05)$. By contrast, OG sheep had lower concentrations of albumin (ALB), glucose (GLU), non-esterified fatty acid (NEFA) and immunoglobulin G (IgG) than those of the LG sheep $(P<0.05)$.

\section{Overall assessment of mapping statistics}

The RNA-Seq of the four pooled liver samples generated a total of 141.8 million raw paired-end reads. Upon quality filtering, approximately $6.4 \mathrm{~Gb}$ remained as highquality sequence data in each sample. Using TopHat2 software, we were able to map more than $74.08 \%$ of clean reads per sample to the reference genome, with $71.66-72.46 \%$ of the reads depicting unique alignment.

Table 2 The effect of overgrazing on sheep serum biochemical parameters

\begin{tabular}{|c|c|c|}
\hline \multirow[t]{2}{*}{ Item } & \multicolumn{2}{|l|}{ Groups } \\
\hline & LG & OG \\
\hline$\overline{\mathrm{ALT}}(\mathrm{IU} / \mathrm{L})$ & $27.70 \pm 9.13^{b}$ & $38.18 \pm 6.36^{a}$ \\
\hline AST (IU/L) & $129.95 \pm 12.04^{b}$ & $146.12 \pm 12.65^{a}$ \\
\hline $\mathrm{ALP}(\mathrm{U} / \mathrm{L})$ & $206.83 \pm 14.87^{b}$ & $273.51 \pm 24.52^{a}$ \\
\hline ALB $(g / L)$ & $30.65 \pm 2.59^{a}$ & $25.12 \pm 3.57^{b}$ \\
\hline TBIL (mmol/L) & $4.29 \pm 0.78^{b}$ & $6.13 \pm 1.04^{a}$ \\
\hline BUN (mmol/L) & $8.92 \pm 0.45^{b}$ & $10.90 \pm 1.19^{a}$ \\
\hline GLU (mmol/L) & $5.86 \pm 1.11^{a}$ & $4.53 \pm 0.94^{b}$ \\
\hline NEFA (mmol/L) & $0.59 \pm 0.03^{a}$ & $0.41 \pm 0.05^{b}$ \\
\hline IL-6 (pg/mL) & $86.08 \pm 20.93^{b}$ & $211.34 \pm 10.27^{a}$ \\
\hline $\lg G(g / L)$ & $18.74 \pm 1.87^{a}$ & $13.26 \pm 1.55^{b}$ \\
\hline
\end{tabular}

Values within a column with different superscript letters represent significant differences at $P<0.05$. Numbers are expressed as the means \pm SD. $(n=6)$ LG Light grazing, OG Overgrazing

ALT Alanine aminotransferase, AST Aspartate aminotransferase, ALP Alkaline phosphatase, ALB Albumin, TBIL Total bilirubin, BUN Blood urea nitrogen, GLU Glucose, NEFA Non-esterified fatty acid, IL Interleukin, IgG, Immunoglobulin $G$ 
The alignment summary of all samples is shown in Table 3. The majority of the reads $(62.20-64.09 \%)$ were mapped to annotated exons, whereas $26.58-27.60 \%$ were mapped to the large regions of intergenic sequences, and only $9.29-11.22 \%$ were localized to intronic regions (Fig. 1). All reads were submitted to the website of the National Center for Biotechnology Information Sequence Read Archive site, with accession number SRP149290.

\section{Gene differential expression analysis}

RNA-Seq results from the LG and OG groups identified 12, 860 genes when annotated to sheep reference genome (Additional file 2: Table S2 and Fig. 2). Using the criteria of $\log 2$ ratio $\geq 1$ and a $P$-value $<0.05$, a total of 50 genes were identified as DEGs (OG group versus LG group) (Table 4). Furthermore, comparative analysis of the LG and OG groups indicated equal numbers of down- and up-regulated genes. More importantly, several of the down-regulated genes were related to detoxification (UGT2B31, GLYAT, GSTA1, RHBG) and immune response (DDX58, LRRC40, $M X 1$, IFI27L2) (Table 4), which played vital roles in sheep health and growth performance.

\section{Confirmation of RNA-Seq experiment}

To evaluate the reliability of our RNA-Seq results, we performed qPCR using aliquots obtained from the nonpooled RNA samples. Five randomly selected proteincoding genes (TNC, AQP7, IFI27L2, ORM1, and LRRC40) were used in this assay. We observed that the RNA sequencing results coincided with the qPCR findings (Fig. 3), thereby confirming the reliability of our RNA-Seq expression data.

\section{GO annotations and pathway analysis of differentially expressed genes}

Gene ontology (GO) was employed for the functional annotation of DEGs in our two study groups. For the category of biological processes, cellular processes, single-organism processes, biological regulation (immune responses) and metabolic processes (energy

Table 3 Summary statistics of sequence quality and alignment information of four pooled liver samples from two groups

\begin{tabular}{lllll}
\hline Sample group & C1 LG & C2 LG & T1 OG & T2 OG \\
\hline Raw reads & $40,726,399$ & $35,081,248$ & $30,387,651$ & $35,584,097$ \\
Clean reads & $37,187,459$ & $31,030,493$ & $25,747,921$ & $32,929,559$ \\
Q30 (\%) & $85.06 \%$ & $85.08 \%$ & $85.13 \%$ & $85.12 \%$ \\
GC Content (\%) & $49.50 \%$ & $49.78 \%$ & $49.91 \%$ & $50.50 \%$ \\
Mapped reads & $27,714,503$ & $23,061,884$ & $19,281,470$ & $24,449,321$ \\
Uniquely mapped reads & $26,783,720$ & $22,292,733$ & $18,655,917$ & $23,595,965$ \\
Mapping ratio (\%) & $74.53 \%$ & $74.32 \%$ & $74.89 \%$ & $74.08 \%$ \\
\hline
\end{tabular}

LG Light grazing, OG Overgrazing metabolism) were the most abundant groups (Fig. 4), thereby suggesting that the impaired forage quantity and quality induce changes in sheep health and growth. In the category of cellular components, the subcategories of cell part, cell, organelle, and membrane were ranked top 3 (Fig. 4). For the molecular functional group, the subcategories of binding (nucleic-acid binding) represented the largest term, followed by catalytic and structural molecular activity. KEGG pathway analysis identified two highly enriched pathways, namely, the peroxisome proliferator-activated receptor (PPAR) signaling pathway $(P=0.0060)$ as well as the ECM-receptor interactions $(P=0.0125)$ (Table 5).

\section{Discussion}

The liver is the major organ in animals that is involved in the metabolism of lipids, nitrogen compounds, as well as energy [19]. Alterations in nutrients metabolic pathways are closely related to animal growth performance and health [20]. In this study, high-throughput transcriptomic analysis integrated with serum parameter analyzes were conducted to elucidate the underlying molecular mechanisms in growth reduced sheep livers in response to consequences of OG. Like previous findings, we observed a negative correlation between elevated GI and growth performance among sheep [6].

The LG and OG groups exhibited differences in the transcript expression of 50 genes. In a previous study, additional energy that would be utilized for animal physical activity are necessary with the increased GI, which in turn reduces the available energy needed for growth and production [3]. Our findings agree with those of Lin et al. (2011) [3], in that we observed changes in genes expression and serum components in relation to energy metabolism because of the lower forage availability. DEGs involved in the PPAR signaling pathway were identified in this study function in lipid metabolism, including aquaporin-7 (AQP7), cytochrome P450 4A6 (CYP4A6) and retinoic acid receptor RXR-gamma $(R X R G)$. These DEGs that are related to lipid metabolism possibly contribute to lipolysis, which occurs in the liver, to provide energy and structural stability to the body [21].

$A Q P s$ are intrinsic membrane proteins that form channels in epithelial and endothelial cells [22]. AQP7 apparently regulates the efflux of lipolysis-derived glycerol from adipocytes, which are essential in the maintenance of normal adiposity [22]. A previous study had shown that $A Q P 7$ is up-regulated by fasting, low insulin and PPAR $\alpha$ and altered expression may be related to lipid metabolism disorders [23]. Similar to these functions, $A Q P 7$ expression was significantly higher in the OG group compared to the LG group, possibly due to the significant decreased in herbage allowance in heavy 


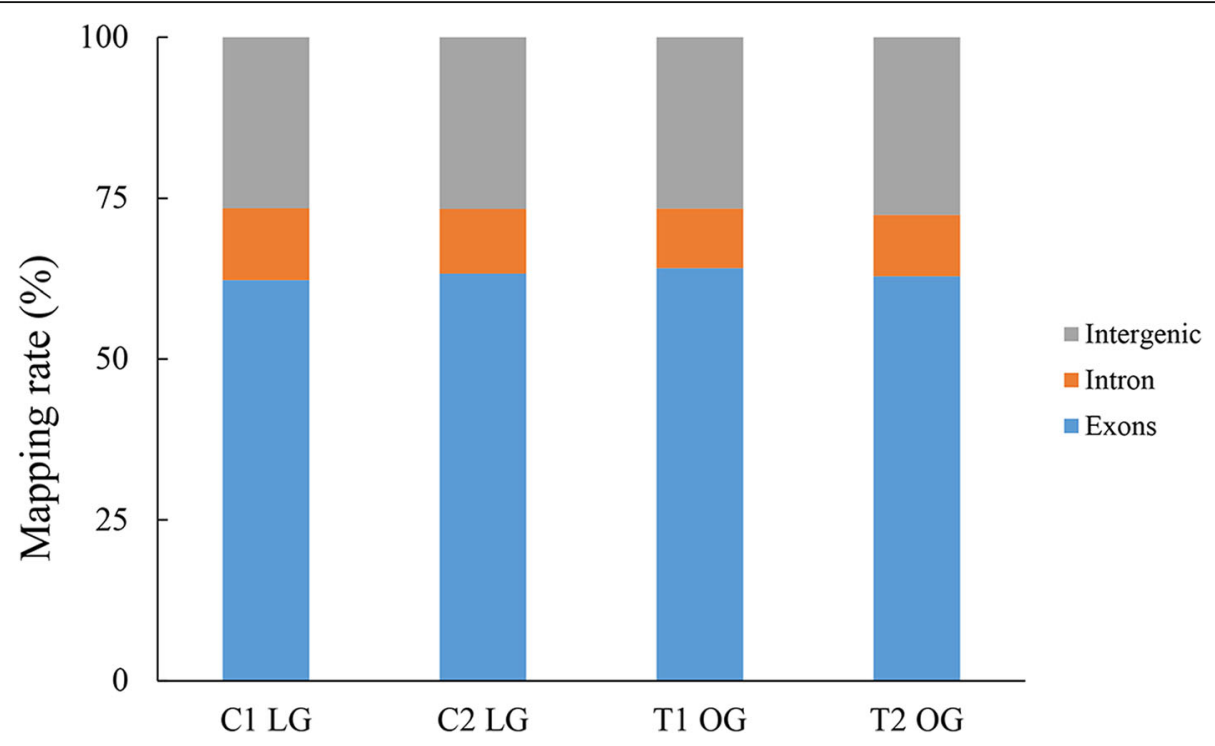

Fig. 1 The percentage of reads mapped to exonic, intronic, and intergenic regions. LG, light grazing; OG, overgrazing. C1 and C2, pooled biological replicates in LG group. T1 and T2, pooled biological replicates in OG group

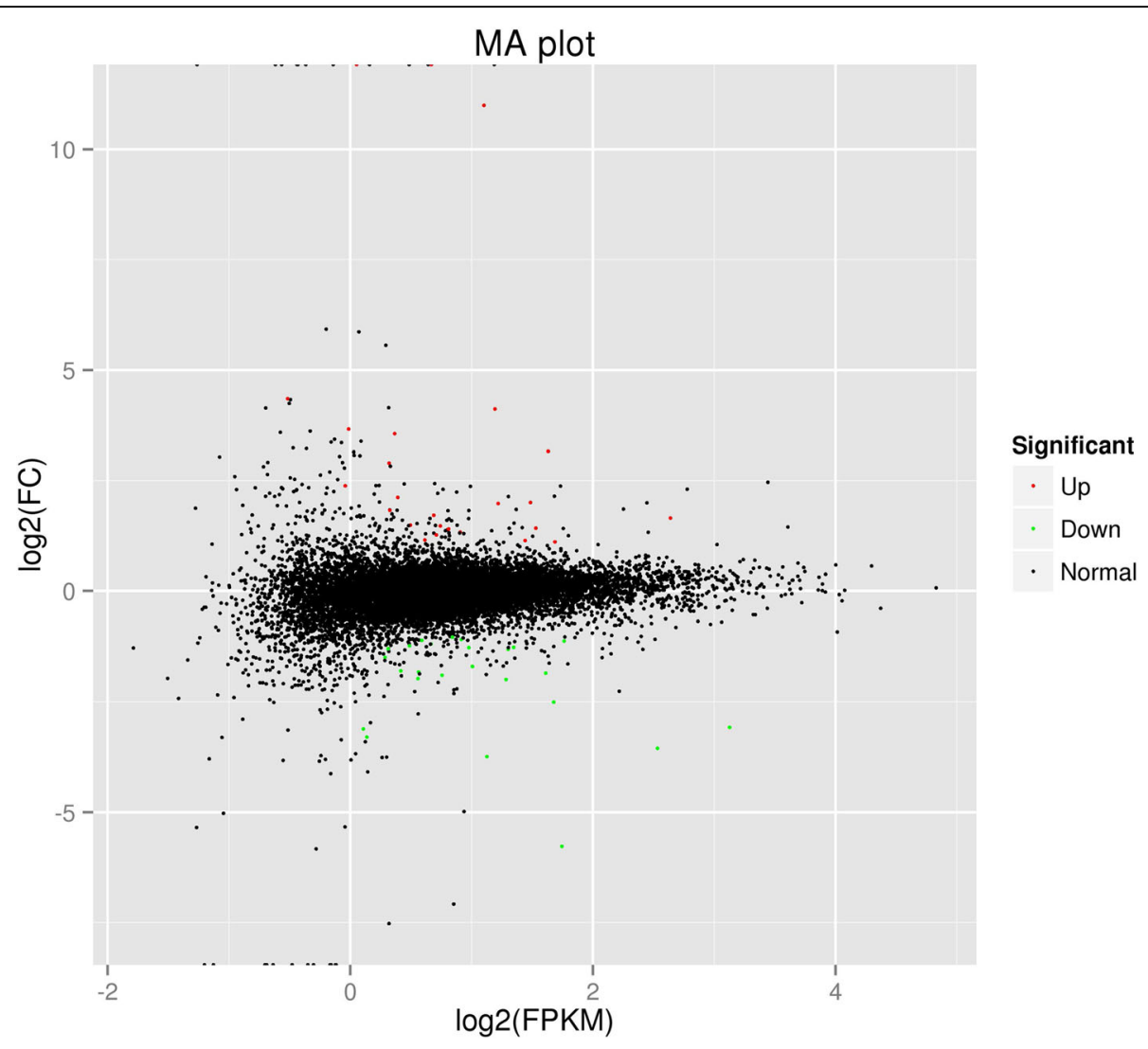

Fig. 2 MA plot. Red dots (Up) represent significantly up-regulated genes $(P<0.05$, fold change $\geq 2)$; green dots (Down) indicate significantly down-regulated genes $(P<0.05$, fold change $\leq 0.5)$; black dots (Normal) show insignificantly differentially expressed genes 
Table 4 Differentially expressed genes in overgrazing group compared to light grazing group

\begin{tabular}{|c|c|c|c|}
\hline Ensemble ID & Gene symbol & Annotation & $\log 2 \mathrm{FC}$ \\
\hline Down-regulated genes & & & Down \\
\hline ENSOARG00000008430 & SCN2B & Sodium channel subunit beta-2 & -5.8 \\
\hline ENSOARG00000009284 & UGT2B31 & UDP-glucuronosyltransferase 2B31 & -3.7 \\
\hline ENSOARG00000014413 & IFI27L2 & Interferon alpha-inducible protein 27-like protein 2 & -3.6 \\
\hline ENSOARG00000018317 & COL4A5 & Collagen alpha-5(IV) chain & -3.3 \\
\hline ENSOARG00000013977 & ROCK2 & Rho-associated protein kinase 2 & -3.1 \\
\hline ENSOARG00000006050 & ORM1 & Alpha-1-acid glycoprotein & -3.1 \\
\hline ENSOARG00000011261 & GLYAT & Glycine N-acyltransferase & -2.5 \\
\hline ENSOARG00000018851 & CEP290 & Centrosomal protein of $290 \mathrm{kDa}$ & -2.0 \\
\hline ENSOARG00000005827 & C1ORF85 & Lysosomal protein NCU-G1 & -2.0 \\
\hline ENSOARG00000017176 & TCTN3 & Tectonic-3 & -1.9 \\
\hline ENSOARG00000011449 & PRLR & Prolactin receptor & -1.9 \\
\hline ENSOARG00000005587 & EXT1 & Exostosin-1 & -1.8 \\
\hline ENSOARG00000020058 & THBS1 & Thrombospondin-1 & -1.8 \\
\hline ENSOARG00000014902 & GSTA1 & Glutathione S-transferase A1, N-terminally processed & -1.7 \\
\hline ENSOARG00000014731 & DDX58 & Probable ATP-dependent RNA helicase DDX58 & -1.5 \\
\hline ENSOARG00000005951 & RHBG & Ammonium transporter Rh type B & -1.3 \\
\hline ENSOARG00000017047 & ALDH1L1 & Cytosolic 10-formyltetrahydrofolate dehydrogenase & -1.3 \\
\hline ENSOARG00000011814 & LRRC40 & Leucine-rich repeat-containing protein 40 & -1.3 \\
\hline ENSOARG00000005886 & PFKFB1 & Fructose-2,6-bisphosphatase & -1.3 \\
\hline Sheep_newGene_2200 & & & -1.2 \\
\hline ENSOARG00000010283 & $M \times 1$ & Interferon-induced GTP-binding protein Mx1, N-terminally processed & -1.2 \\
\hline ENSOARG00000012673 & RCAN1 & Calcipressin-1 & -1.1 \\
\hline ENSOARG00000017875 & COL8A1 & Vastatin & -1.1 \\
\hline ENSOARG00000010155 & RNF144B & E3 ubiquitin-protein ligase RNF144B & -1.1 \\
\hline ENSOARG00000019483 & FOS & Proto-oncogene c-Fos & -1.0 \\
\hline Up-regulated genes & & & Up \\
\hline Sheep_newGene_75 & & & Inf \\
\hline Sheep_newGene_7857 & & & $\operatorname{lnf}$ \\
\hline ENSOARG00000011401 & RXRG & Retinoic acid receptor RXR-gamma & 11.0 \\
\hline Sheep_newGene_4617 & & & 4.4 \\
\hline Sheep_newGene_7585 & SULT3A1 & Amine sulfotransferase & 4.1 \\
\hline ENSOARG00000000581 & LRRC31 & Leucine-rich repeat-containing protein 31 & 3.7 \\
\hline ENSOARG00000003294 & CYP4A6 & Cytochrome P450 4A6 & 3.6 \\
\hline ENSOARG00000009458 & AQP7 & Aquaporin-7 & 3.2 \\
\hline Sheep_newGene_1150 & & & 2.9 \\
\hline ENSOARG00000013615 & FSTL1 & Follistatin-related protein 1 & 2.4 \\
\hline ENSOARG00000010334 & KLKB1 & Plasma kallikrein light chain & 2.1 \\
\hline ENSOARG00000010449 & $\mathrm{DHDH}$ & Dihydrodiol dehydrogenase 3 & 2.0 \\
\hline ENSOARG00000005941 & TNC & Tenascin & 2.0 \\
\hline Sheep_newGene_3 & & & 1.8 \\
\hline ENSOARG00000009239 & $\mathrm{BCL3}$ & B-cell lymphoma 3 protein & 1.7 \\
\hline ENSOARG00000004859 & $\mathrm{HOP}$ & Homeodomain-only protein & 1.7 \\
\hline ENSOARG00000004234 & SLC45A3 & Solute carrier family 45 member 3 & 1.5 \\
\hline
\end{tabular}


Table 4 Differentially expressed genes in overgrazing group compared to light grazing group (Continued)

\begin{tabular}{clll}
\hline Ensemble ID & Gene symbol & Annotation & log2FC \\
\hline ENSOARG00000000804 & POC1B & POC1 centriolar protein homolog B & 1.5 \\
ENSOARG00000011986 & RPL10A & 60S ribosomal protein L10a & 1.4 \\
ENSOARG00000013534 & MYOC & Myocilin, C-terminal fragment & 1.4 \\
ENSOARG00000010264 & PDLIM2 & PDZ and LIM domain protein 2 & 1.3 \\
Sheep_newGene_8346 & CFH & Complement factor H & 1.3 \\
ENSOARG00000000813 & TECPR1 & Tectonin beta-propeller repeat-containing protein 1 & 1.2 \\
ENSOARG00000020020 & TUBA4A & Tubulin alpha-4A chain & 1.1 \\
ENSOARG00000017743 & SLC51B & Organic solute transporter subunit beta & 1.1 \\
\hline
\end{tabular}

FC Fold change, Inf, positive infinity, it indicates that the gene is only expressed in the overgrazing group

grazed areas [3]. The transcriptional activation of CYP4A6 in response to peroxisome proliferators can be mediated by PPAR $\alpha$, and the peroxisome proliferators are accompanied by the induction of enzymes involved in fatty acid oxidation caused by fasting [24]. Therefore, CYP4A6 might function as an indicator of extra fatty acid oxidation in sheep induced by the shortage of herbage under the OG condition. $R X R G$ is an important regulator of fatty acid metabolism and $\beta$-oxidation depending on the binding of RXR ligands or PPAR ligands [25]. The up-regulated expression of RXRG reflects a metabolic adaption to a higher lipolysis and fatty acid turnover due to their regulatory roles [13]. The elevated expression of RXRG in the OG group might reflect similar mechanisms to those provided by Boergesen et al. (2012) and Óvilo et al. (2014) [13, 26] that increases hepatic fatty acid oxidation. In this study, lower herbage availability caused by $O G$ was associated with increased expression of $A Q P 7, C Y P 4 A 6$ and RXRG, inducing lipolysis and fatty acid oxidation, which is consistent with previous research [3]. In addition to the molecular evidence shown in the hepatic transcriptome, serum levels of GLU and NEFA, which are important energy sources, were greatly decreased in the OG sheep. The above combined results indicated that the shortage of forage availability increased sheep physical activity, which in turn reduced the available energy for growth and production under the OG condition.

In addition to lipid metabolism, the liver also serves as the site of detoxification, thereby eliminating endogenous toxic compounds that are generated during metabolism or exogenous xenobiotics [27]. In this study, four DEGs related to detoxification were down-regulated in OG sheep livers. Primarily expressed in the liver, UDPglucuronosyltransferase 2B31 (UGT2B31) is one of the most important xenobiotic metabolizing enzymes that conjugate a wide range of xenobiotics [28]. Glycine Nacyltransferase (GLYAT) plays a major role in maintaining hepatic homeostasis and contributes to glycine conjugation of xenobiotics as well as endogenous metabolites that

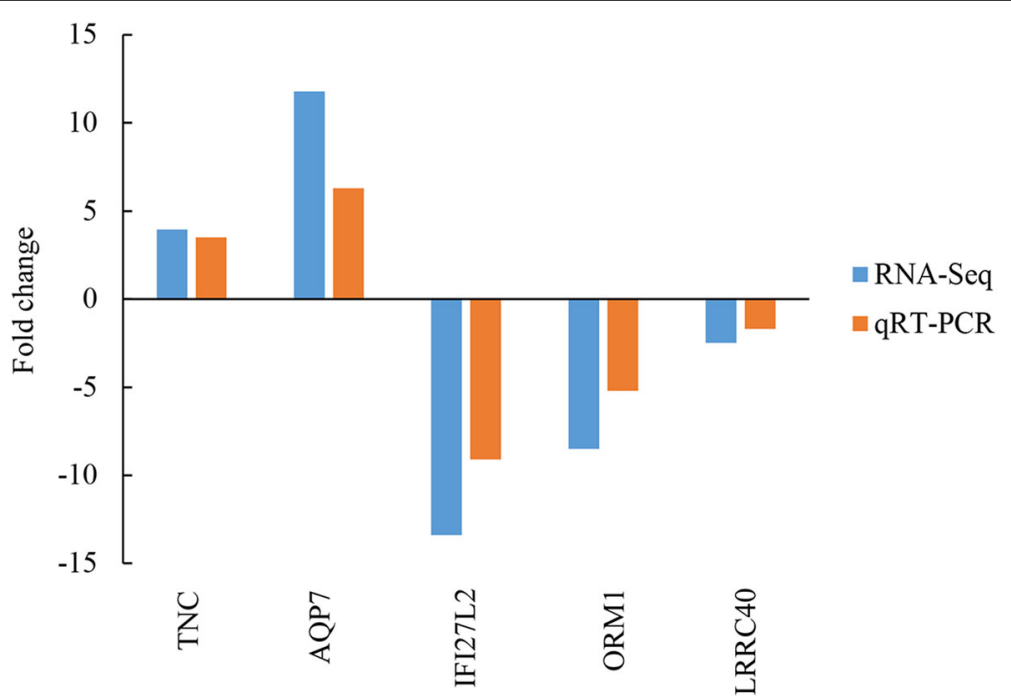

Fig. 3 qRT-PCR validation of differentially expressed genes in sheep livers. $\beta$-actin (ACTB) was used as an internal reference, and the data are expressed as fold-change ( $n=6$ per group) 


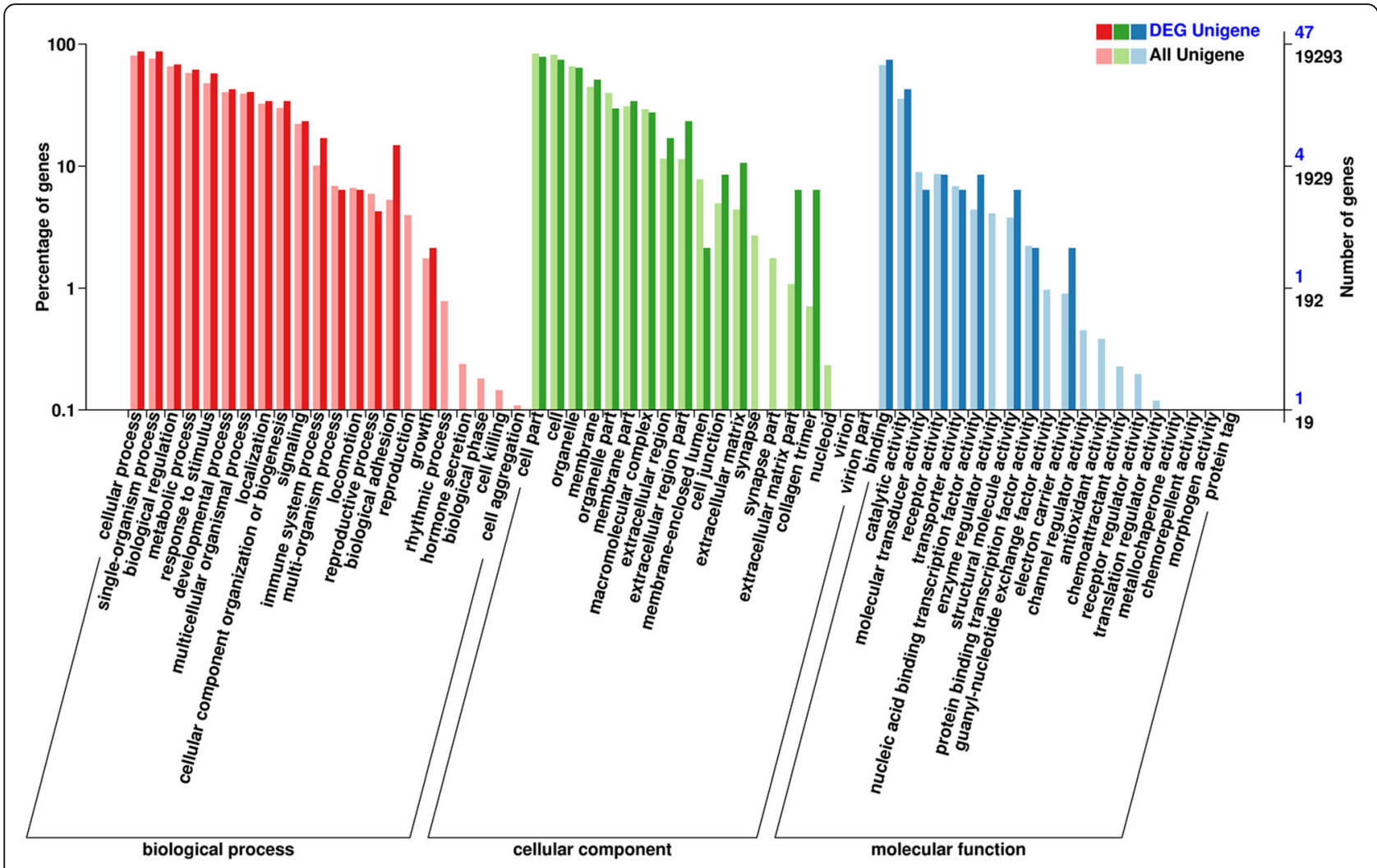

Fig. 4 Gene ontology (GO) annotation of unigenes and differentially expressed genes (DEGs) in light grazing sheep as well as overgrazing sheep

are involved in inhibition fatty acid oxidation in hepatic tissues [29]. The glutathione S-transferases (GSTs) pertain to a superfamily of isoenzymes that are involved in the detoxification of xenobiotics and endobiotics, cellular protection from oxidative stress, and regulation of signaling pathways [30]. Glutathione S-transferase A1 (GSTA1) is the predominant GST in the liver and participates in the metabolism of lipid peroxidation products [30]. Ammonium transporter Rh type B (RHBG) is an ammonia transporter, which is preferentially expressed in the sheep liver for acid-base homeostasis [31]. Genetic deletion of $R H B G$ alters basal ammonia excretion in response to an acid load. The down-regulation of these genes indicates impairment of hepatic detoxification in the OG group, which coincides with the observed elevated serum ALT, AST, ALP, TBIL and BUN levels. Impairment of hepatic detoxification in the OG group might be triggered by a shift in

Table 5 Pathways that are significantly enriched with differentially expressed genes

\begin{tabular}{lll}
\hline Pathway name & Enriched genes & $P$-value \\
\hline PPAR signaling pathway & RXRG, CYP4A6, AQP7 & 0.0060 \\
ECM-receptor interaction & COL4A5, THBS1, TNC & 0.0125 \\
\hline
\end{tabular}

RXGH Retinoic acid receptor RXR-gamma, CYP4A6 Cytochrome P450 4A6; AQP7, aquaporin-7; COL4A5 Collagen alpha-5(IV) chain, THBS1

Thrombospondin-1, TNC Tenascin energy sources; namely, from carbohydrates to fatty acids and proteins, which may be due to shortage of forage allowance induced excessive physical activity and unequal levels of gross energy and CP levels in the forage. This speculation is consistent with our demonstration in the previous study [19].

In addition to PPAR signaling pathway, ECM-receptor interaction was significantly enriched in liver transcriptome of OG sheep. As reported in previous study, dysregulation of this pathway in hepatic tissue or cell can induce liver injury and apoptosis [32]. Because the ECM plays an important role in maintaining cell structure and function [33]. We observed in liver transcriptome lower expression of collagen gene (collagen alpha-5(IV) chain) (COL4A5) and altered expression of thrombospondin-1 (THBS1) and tenascin (TNC) in the OG group that could lead to disruption of the ECM [32, 34]. The above alterations of transcriptome profile combined with the increased serum level of IL-6, suggests that the imbalanced forage nutrients composition may trigger the pathological change of sheep liver. However, additional determinations are still required on histological evidences such as HE staining, immunohistochemical staining and so on in the future.

The liver is an important immune organ that contributes to protection from bacterial or viral infection and 
anti-inflammatory reactions [35]. The OG group showed that four immune response-related genes were downregulated. Probable ATP-dependent RNA helicase DDX58 (DDX58), Leucine-rich repeat-containing protein 40 (LRRC40), and interferon-induced GTP-binding protein $\mathrm{Mx} 1(M X 1)$ are related to the activation of the innate immune system, thereby driving adaptive immune responses [36-39]. Interferon alpha-inducible protein 27-like protein 2 (IFI27L2) is one of a family of cytokines with antiviral function [40]. The down-regulation of these genes implies that the sheep immune system has been suppressed under OG conditions, which increases the likelihood of pathogenic infections and decreases growth performance. This observation coincides with the decreased immune indices and serum IgG levels of the OG sheep. Moreover, an anti- inflammatory reaction-related gene was down-regulated in the OG group. Alpha-1-acid glycoprotein (ORM1) possesses some anti-inflammatory and immunomodulatory properties and is primarily expressed in the liver in various species [41]. ORM1 down-regulation in the OG sheep might lead to chronic stress, which coincides with the higher serum levels of inflammatory cytokines. We propose that the DEGs related to detoxification, immune response and anti-inflammatory reaction altered by degraded forage quality collectively indicated that the health status of sheep was severely impaired under in the OG group, which might be another important reason for the reduced growth performance.

\section{Conclusion}

In summary, the transcriptome analysis has shown that consequences of OG leads to differential abundances of various hepatic genes in sheep. Furthermore, highthroughput RNA sequencing and serum biochemical analysis revealed that lower forage availability and quality induces alterations in energy metabolism (i.e., lipid metabolism) as well as detoxification and immune responses, resulting in lipolysis and impaired health status, ultimately reducing sheep growth. The results of the present study provide a foundation for the development of gene interactive networks that are involved in OG induced side effects as well as nutritional strategies to enhance sheep growth performance under OG conditions.

\section{Methods}

This research was performed at the Institute of Grassland Research, the Chinese Academy of Agricultural Sciences Research Station in the summer 2016. The station is situated in the Xilin River basin of Inner Mongolia Autonomous Region of China (116 $32^{\prime}$ E, $\left.44^{\circ} 15^{\prime} \mathrm{N}\right)$. Its natural vegetation is predominated by three grass species: namely, Leymus chinensis, Stipa krylovii, and S. grandis.

\section{Experimental design and animals}

In June 2016, a total of 48 adult Uzhumchin wethers (24-month-old; initial live weight (LW):33.2 $\pm 3.9 \mathrm{~kg}$ ) were purchased from Xinshengia Sheep Breeding company (Xilin Hot, Inner Mongolia, China). The animals were randomly distributed to the LG (4 sheep/ plot) and the OG (12 sheep/plot) groups. The experimental site was consisted of 6 total plots (1.33 ha/ plot, 3 plots per each grazing group). Therefore, two different stocking rates (SRs) were formed: 3.0 (LG) and 9.0 sheep/ha (OG). The animals grazed continuously in the plots throughout the entire grazing experiment (June 5 to September 3, 90 days). The sheep received treatment for internal parasites at the start of the investigation and were provided water and mineral lick stones ad libitum.

\section{Sample collection}

To determine chemical composition, the forages were pooled each month until completion of the grazing experiment. The procedure of collecting forages was as previously described [42] and details are presented in Additional file 3. Various chemical composition indices of the collected forages were assessed, which included $\mathrm{CP}$, gross energy, NFE, NDF, ADF, and ADL, as previously described [6]. The live weight (LW) of the animals were determined the first and the last day (following 12-h fasting) of the grazing study and used in calculating the mean daily gain. Blood were then collected from two randomly selected sheep from each plot in the two GI groups $(n=6$ for each group) via venopuncture of the cervical vein and into vacuum tubes. The blood samples were then centrifuged twice at $2000 \mathrm{~g}$ at $4{ }^{\circ} \mathrm{C}$ for $30 \mathrm{~min}$, followed by $400 \mathrm{~g}$ at $4{ }^{\circ} \mathrm{C}$ for $10 \mathrm{~min}$, to separate the sera, which were then stored at $-80^{\circ} \mathrm{C}$ until analysis. The sheep used in blood extraction were sacrificed by $\mathrm{CO}_{2}$ asphyxiation for liver sample collection using standard procedures approved by the Chinese Academy of Agricultural Sciences (2 sheep per plot, $n=6$ for each group). Immediately, after exsanguination, the spleen and liver were isolated and weighed and used in the calculation of immune organ indices. For liver transcriptome and qPCR analyses, right away after weighting, 2 grams of each liver sample were washed in ice-cold, sterile PBS, frozen in liquid nitrogen, and then stored at $-80^{\circ} \mathrm{C}$.

\section{Serum biochemical analyses}

For biochemical analysis, serum concentrations of ALT, AST, ALP, ALB, TBIL, BUN, GLU, NEFA, IL-6 and IgG were assessed using a corresponding diagnostic kit (Nanjing Jiancheng Bioengineering Institute, Nanjing, China), following the manufacturer's instructions. 


\section{RNA isolation and sequencing}

The liver samples of the 12 sacrificed sheep (six sheep per group) were respectively ground in liquid nitrogen. Total RNA was extracted from the liver samples using TRIzol $^{\circ}$ (Invitrogen, USA) following the manufacturer's instructions. RNA parameters such as purity, quantity, and quality were respectively assessed using a NanoPhotometer spectrophotometer (Implen, USA), Qubit 2.0 Fluorimeter (Life Technologies, USA), and Agilent 2100 Bioanalyzer (Agilent Technologies, USA), which revealed that all samples possessed an RNA integrity number (RIN) higher than 8.0 and the $28 \mathrm{~S} / 18 \mathrm{~S}$ ratio of the qualified RNA ranged from 1.8 to 2.0 .

To minimize inter-individual variability, equal amounts of total RNA from three sheep of the same group were pooled into a single biological replicate, and two biological replicates were prepared for each group [43]. One microgram of RNA from each biological replicate was employed as template. To construct the sequencing libraries (a total of four libraries, which includes two biological replicates $x$ two groups), a NEBNext ${ }^{\circ}$ Ultra $^{\text {Tw }}$ RNA Library Prep Kit for Illumina ${ }^{\circ}$ (NEB, USA) was employed following the recommendations of the manufacturer, using index codes for each biological replicate.

The index-coded biological replicates were clustered on a cBot Cluster Generation System with a TruSeq PE Cluster Kit v4-cBot-HS (Illumia, USA) following the manufacturer's instructions. Then, the libraries were sequenced using an Illumina HiSeq 2500 system, generating paired-end reads.

\section{Sequenced data processing}

The raw reads in FASTQ format were first processed using the FASTX-Toolkit (version: 0.0.13). Here, reads with adapter sequences, low quality $3^{\prime}$ end, containing poly-N, rRNA, sequences shorter than $20 \mathrm{nt}$ and low quality with $\mathrm{Q}<20$ were eliminated, and the remaining reads were designated as clean reads. We then assessed the resulting clean data in terms of Q30 value, GCcontent, and extent of sequence duplication. All subsequent analyses were then based on high quality, clean data. The clean reads from every library were subsequently mapped to the reference genome of sheep (Ovis_aries.Oar_v3.1.74.toplevel.fa, Ensembl release 74) using the TopHat2 (version: 2.0.9). Reads showing a perfect match or a single mismatch were further evaluated and annotated in relation to the reference genome.

\section{Differential gene expression and functional analysis}

Normalization of expression levels of each gene was performed using fragments per kilo base per million mapped reads (FPKM) method. The differentially expressed genes (DEGs) between the LG and the OG groups were detected using the DESeq $\mathrm{R}$ package. The false discovery rate (FDR) was subjected to Benjamini and Hochberg correction to adjusted $P$-value. An adjusted $P$-value $<0.05$ and a $\log 2$ ratio $\geq 1$ were used as criteria in selecting significant DEGs. The identified DEGs were functionally annotated using gene ontology (GO), and the Blast2Go program for the categories of biological process, cellular component, and molecular function. The Kyoto Encyclopedia of Genes and Genomes (KEGG) was used to predict metabolic pathways, and statistical enrichment of DEGs for various biological processes and pathways was performed using the KOBAS.

\section{Experimental validation by quantitative real-time PCR (qRT-PCR)}

To assess the repeatability and reproducibility of our gene expression data, which were obtained using RNASeq of sheep liver, qRT-PCR was conducted on five randomly selected genes from the significant DEGs using the extracted total RNA (a total of 12 individual liver samples, $n=6$ for each group) as template. The PrimeScript $^{\text {tix }}$ Reverse Transcriptase, D2680A (Takara Biotechnology, China) was employed in first-strand cDNA synthesis. Gene expression levels were assessed using an Applied Biosystems 7500 Fast Real-Time PCR System (Foster City, USA) and a PrimeScript ${ }^{\mathrm{Tm}} \mathrm{RT}$ reagent Kit, RR037A (SYBR Green) (Takara Biotechnology, China). The sequences of the primers used in this study are presented in Additional file 4: Table S3, which were designed using primer premier 5.0. The sheep $\beta$-actin $(A C T B)$ gene was used as an internal control $[44,45]$ to normalize mRNA levels, which was consistently stable among the experimental groups and among several other internal control genes examined including glyceraldehyde 3-phosphate dehydrogenase (GAPDH), $60 \mathrm{~S}$ ribosomal protein L19 (RPL19) and 60S acidic ribosomal protein P0 (RPLPO) using BestKeeper software (Additional file 5: Figure S1). The reaction mixtures were incubated in a 96-well plate at $95^{\circ} \mathrm{C}$ for $30 \mathrm{~s}$, followed by 40 cycles of $95^{\circ} \mathrm{C}$ for $10 \mathrm{~s}, 60^{\circ} \mathrm{C}$ for $30 \mathrm{~s}$. All measurements were conducted in triplicates. Relative mRNA expression levels were calculated to the $\mathrm{Ct}$ value obtained for the housekeeping control gene $(A C T B)$ using the $2^{-\Delta \Delta C T}$ method [46].

\section{Statistical analyses}

Statistical analyses were conducted using SPSS Statistics 17.0 (SPSS, Inc., USA). The results were presented as the mean $\pm S D$. Differences in forage nutritional contents, sheep growth performance, serum parameters and gene expression levels between the two groups were evaluated using two-tailed Student's $t$ test, and significance was established at a $P<0.05$. 


\section{Additional file}

Additional file 1: Table S1. The effect of overgrazing on major nutritional indices of herbage. (DOC $33 \mathrm{~kb}$ )

Additional file 2: Table S2. RNA-Seq data of all identified genes $(n=12,860)$ in the study. (XLSX $1428 \mathrm{~kb})$

Additional file 3: The detailed description of herbage sample collection. (DOC $28 \mathrm{~kb}$ )

Additional file 4: Table S3. The primers used for the $\mathrm{qPCR}$ analysis. (DOC 29 kb)

Additional file 5: Figure S1. Analysis of 4 reference genes standard deviation (SD) value using BestKeeper. Reference genes with an SD below 1 are considered stably expressed, and a smaller SD indicates a more stable reference gene. The result showed that ACTB is the most stable gene. (TIFF $379 \mathrm{~kb}$ )

\section{Abbreviations}

DEGs: Differentially expressed genes;; GO: Gene Ontology; KEGG: Kyoto Encyclopedia of Genes and Genomes; LG: Light grazing; NCBI: National Center for Biotechnology Information; OG: Overgrazing

\section{Acknowledgements}

We thank American Journal Experts and LetPub for their linguistic assistance during the preparation of this manuscript.

\section{Authors' contributions}

WR and JZ developed and framed the research questions. WR and JZ analyzed transcriptomics data. YD and YG contributed to serum biochemical analysis and subsequent data analysis. WB and HG contributed to revise the entire manuscript. WR and JZ drafted the manuscript. All authors have read and approved the manuscript.

\section{Funding}

This work was funded by the Fundamental Research Funds for Central Nonprofit Research Institutes (1610332016010), the Chinese National Key Basic Research and Development Program (2014CB138804) and the Chinese National Key Technology Research and Development Program (2012BAD13B07). The funders had no role in study design, data collection and analysis, decision to publish, or the manuscript preparation.

\section{Availability of data and materials}

The data supporting the results of this article are included within the article and in its additional files.

\section{Ethics approval and consent to participate}

This study was conducted in strict accordance with the Regulations for the Administration of Affairs Concerning Experimental Animals of the State Council of the People's Republic of China. The protocol was approved by the Committee on Experimental Animal Management of the Chinese Academy of Agricultural Sciences (Approval No. 45/27.05.2016).

\section{Consent for publication}

Not applicable.

\section{Competing interests}

The authors declare that they have no competing interests.

\section{Author details}

${ }^{1}$ Key Laboratory of Forage Grass, Ministry of Agriculture, Institute of Grassland Research, Chinese Academy of Agricultural Sciences, Hohhot 010010, Inner Mongolia, China. ${ }^{2}$ NSW Department of Primary Industries, Orange Agricultural Institute, Orange, NSW 2800, Australia. ${ }^{3}$ College of Life Sciences, Inner Mongolia Agricultural University, Hohhot 010019, Inner Mongolia, China. ${ }^{4}$ College of Animal Science and Technology, Jilin Agricultural University, Changchun 130018, Jilin, China.
Received: 4 February 2019 Accepted: 26 June 2019

Published online: 04 July 2019

\section{References}

1. Lin L, Dickhoefer U, Müller K, Wang C, Glindemann T, Hao J, et al. Growth of sheep as affected by grazing system and grazing intensity in the steppe of Inner Mongolia, China. Livest Sci. 2012:144(1-2):140-7.

2. Zuo Z, Zhang M, Gao J, Wen S, Hou P, Gao Y. Allelopathic effects of Artemisia frigida Willd. On growth of pasture grasses in Inner Mongolia, China. Biochem Syst Ecol. 2011;39(4-6):377-83.

3. Lin L, Dickhoefer U, Müller K, Susenbeth A. Grazing behavior of sheep at different stocking rates in the inner Mongolian steppe, China. Appl Anim Behav Sci. 2011;129(1):36-42.

4. Wang CJ, Tas BM, Glindemann T, Mueller K, Schiborra A, Schoenbach P, et al. Rotational and continuous grazing of sheep in the inner Mongolian steppe of China. J Anim Physiol Anim Nutr. 2009;93(2):245-52.

5. Zhang R, Zhang W, Zuo Z, Li R, Wu J, Gao Y. Inhibition effects of volatile organic compounds from Artemisia frigida Willd. On the pasture grass intake by lambs. Small Ruminant Res. 2014;121(2-3):248-54

6. Glindemanna T, Wang C, Tas B, Schiborrab A, Gierusb M, Taubeb F, et al. Impact of grazing intensity on herbage intake, composition, and digestibility and on live weight gain of sheep on the inner Mongolian steppe. Livest Sci. 2009;124(1-3):142-7.

7. Dickhoefer U, Bösing BM, Hasler M, Hao J, Lin L, Müller K, et al. Anima responses to herbage allowance: forage intake and body weight gain of sheep grazing the inner Mongolian steppe - results of a six-year study. J Anim Sci. 2016;94(5):2059-71.

8. Nemeth E, Baird W, O'Farrelly C. Microanatomy of the liver immune system. Semin Immunopathol. 2009;31(3):333-43.

9. Trauner M, Meier PJ, Boyer JL. Molecular pathogenesis of cholestasis. N Engl J Med. 1998:339(17):1217-27.

10. Jiang $X$, Zeng $T$, Zhang S, Zhang Y. Comparative proteomic and bioinformatic analysis of the effects of a high-grain diet on the hepatic metabolism in lactating dairy goats. PLoS One. 2013;8(11):e80698.

11. Garcia F, Carrère P, Soussana F, Baumont R. The ability of sheep at different stocking rates to maintain the quality and quantity of their diet during the grazing season. J Agr Sci. 2003;140(1):113-24.

12. Lachica M, Aguilera F. Energy expenditure of walk in grassland for small ruminants. Small Ruminant Res. 2005:59(2-3):105-21.

13. Óvilo C, Benítez R, Fernández A, Isabel B, Núñez Y, Fernández Al, et al. Dietary energy source largely affects tissue fatty acid composition but has minor influence on gene transcription in Iberian pigs. J Anim Sci. 2014;92(3): 939-54.

14. Wang S, Li W, Liu Y, Li H, Ma Y, Zhang Z. Comparative transcriptome analysis of shortened fruit mutant in woodland strawberry (Fragaria vesca) using RNA-Seq. J Integr Agr. 2017;16(4):828-44.

15. Li H, Wang TXC, Wang D, Ren J, Li Y, et al. Transcriptome profile of liver at different physiological stages reveals potential mode for lipid metabolism in laying hens. BMC Genomics. 2015;16:763.

16. Yi B, Chen $L$, Sa R, Zhong $\mathrm{R}$, Xing $\mathrm{H}$, Zhang $\mathrm{H}$. High concentrations of atmospheric ammonia induce alterations of gene expression in the breast muscle of broilers (Gallus gallus) based on RNA-Seq. BMC Genomics. 2016; 17(1):598

17. Laporta J, Rosa GJ, Naya H, Carriquiry M. Liver functional genomics in beef cows on grazing systems: novel genes and pathways revealed. Physiol Genomics. 2014:46(4):138-47.

18. Grala TM, Kay JK, Phyn CV, Bionaz M, Walker CG, Rius AG, et al. Reducing milking frequency during nutrient restriction has no effect on the hepatic transcriptome of lactating dairy cattle. Physiol Genomics. 2013;45(23):1157-67.

19. Ren W, Hou X, Wang Y, Badgery W, Li X, Ding Y, et al. Overgrazing induces alterations in the hepatic proteome of sheep (Ovis aries): an iTRAQ-based quantitative proteomic analysis. Proteome Sci. 2017;15:2.

20. Zhang J, Gao Y, Lu Q, Sa R, Zhang H. Proteome changes in the small intestinal mucosa of growing pigs with dietary supplementation of nonstarch polysaccharide enzymes. Proteome Sci. 2017:15:3.

21. Xu F, Liu Y, Zhao H, Yu K, Song M, Zhu Y, et al. Aluminum chloride caused liver dysfunction and mitochondrial energy metabolism disorder in rat. Inorg Biochem. 2017;174:55-62

22. Wakayama Y, Hirako S, Jimi T, Shioda S. AQP7 up-regulation in the skeletal muscles of mice with diet induced obesity. J Cell Sci Ther. 2015;6:205. 
23. Kishida K, Kuriyama H, Funahashi T, Shimomura I, Kihara S, Ouchi N, et al. Aquaporin adipose, a putative glycerol channel in adipocytes. J Biol Chem 2000;275(27):20896-902.

24. Johnson EF, Palmer CN, Hsu MH. The peroxisome proliferator-activated receptor: transcriptional activation of the CYP4A6 gene. Ann N Y Acad Sci. 1996:804:373-86.

25. Ouamrane L, Larrieu G, Gauthier B, Pineau T. RXR activators molecular signalling: involvement of a PPAR alpha-dependent pathway in the liver and kidney, evidence for an alternative pathway in the heart. $\mathrm{Br} \mathrm{J}$ Pharmacol. 2003;138(5):845-54.

26. Boergesen M, Pedersen TÅ, Gross B, van Heeringen SJ, Hagenbeek D, Bindesbøll C, et al. Genome-wide profiling of liver $X$ receptor, retinoid $X$ receptor, and peroxisome proliferator-activated receptor a in mouse liver reveals extensive sharing of binding sites. Mol Cell Biol. 2012;32(4):852-67.

27. Arjinajarn P, Chueakula N, Pongchaidecha A, Jaikumkao K, Chatsudthipong $\checkmark$, Mahatheeranont S, et al. Anthocyanin-rich Riceberry bran extract attenuates gentamicin-induced hepatotoxicity by reducing oxidative stress, inflammation and apoptosis in rats. Biomed Pharmacother. 2017;92:412-20.

28. Kondo T, Ikenaka Y, Nakayama SMM, Kawai YK, Mizukawa H, Mitani Y, et al. UDP-glucuronosyltransferase (UGT) 2B subfamily interspecies differences in carnivores. Toxicol Sci. 2017;158(1):90-100.

29. van der Sluis R, Badenhorst CP, Erasmus E, van Dyk E, van der Westhuizen $\mathrm{FH}$, van Dijk AA. Conservation of the coding regions of the glycine $\mathrm{N}$ acyltransferase gene further suggests that glycine conjugation is an essential detoxification pathway. Gene. 2015;571(1):126-34.

30. Martínez-Guzmán C, Cortés-Reynosa P, Pérez-Salazar E, Elizondo G. Dexamethasone induces human glutathione $\mathbf{S}$ transferase alpha 1 (hGSTA1) expression through the activation of glucocorticoid receptor (hGR). Toxicology. 2017;385:59-66.

31. Xiang R, Oddy VH, Archibald AL, Vercoe PE, Dalrymple BP. Epithelial, metabolic and innate immunity transcriptomic signatures differentiating the rumen from other sheep and mammalian gastrointestinal tract tissues. PeerJ. 2016;4:e1762.

32. Liu R, Printz RL, Jenkins EC, O'Brien TP, Te JA, Shiota M, et al. Genome-wide gene expression changes associated with exposure of rat liver, heart, and kidney cells to endosulfan. Toxicol in Vitro. 2018;48:244-54

33. Kim SH, Turnbull J, Guimond S. Extracellular matrix and cell signalling: the dynamic cooperation of integrin, proteoglycan and growth factor receptor. J Endocrinol. 2011;209(2):139-51.

34. Benbow JH, Thompson KJ, Cope HL, Brandon-Warner E, Culberson CR, Bossi $\mathrm{KL}$, et al. Diet-induced obesity enhances progression of hepatocellular carcinoma through Tenascin-C/toll-like receptor 4 signaling. Am J Pathol. 2016;186(1):145-58.

35. Racanelli $\mathrm{V}$, Rehermann B. The liver as an immunological organ. Hepatology. 2006;43(2 Suppl 1):S54-62.

36. Edwards DK, Jasny E, Yoon H, Horscroft N, Schanen B, Geter T, et al. Adjuvant effects of a sequence-engineered mRNA vaccine: translational profiling demonstrates similar human and murine innate response. J Transl Med. 2017;15(1):1

37. Wenger $Y$, Buzgariu W, Reiter S, Galliot B. Injury-induced immune responses in hydra. Semin Immunol. 2014;26(4):277-94.

38. Razali N, Abdul Aziz A, Lim CY, Mat Junit S. Investigation into the effects of antioxidant-rich extract of Tamarindus indica leaf on antioxidant enzyme activities, oxidative stress and gene expression profiles in HepG2 cells. PeerJ. 2015;3:e1292.

39. Xiao J, Yan J, Chen H, Li J, Tian Y, Tang L, Feng H. Mx1 of black carp functions importantly in the antiviral innate immune response. Fish Shellfish Immunol. 2016;58:584-92.

40. Haller O, Kochs $G$, Weber F. The interferon response circuit: induction and suppression by pathogenic viruses. Virology. 2006;344(1):119-30.

41. Ramsay TG, Stoll MJ, Blomberg le A, Caperna TJ. Regulation of cytokine gene expression by orosomucoid in neonatal swine adipose tissue. J Anim Sci Biotechnol. 2016;17:25.

42. Hao J, Dickhoefer U, Lin L, Müller K, Glindemann T, Schönbach P, et al. Effects of rotational and continuous grazing on herbage quality, feed intake and performance of sheep on a semi-arid grassland steppe. Arch Anim Nutr. 2013;67(1):62-76.

43. Chatchaiphan S, Srisapoome P, Kim JH, Devlin RH, Na-Nakorn U. De novo transcriptome characterization and growth-related gene expression profiling of diploid and triploid bighead catfish (Clarias macrocephalus Günther, 1864). Mar Biotechnol (NY). 2017;19(1):36-48.
44. Armstrong E, Iriarte A, Nicolini P, De Los Santos J, Ithurralde J, Bielli A, et al. Comparison of transcriptomic landscapes of different lamb muscles using RNA-Seq. PLoS One. 2018;13(7):e0200732.

45. Basse AL, Dixen K, Yadav R, Tygesen MP, Qvortrup K, Kristiansen K, et al. Global gene expression profiling of brown to white adipose tissue transformation in sheep reveals novel transcriptional components linked to adipose remodeling. BMC Genomics. 2015;16:215.

46. Zhang JZ, Gao Y, Lu QP, Sa RN, Zhang HF. iTRAQ-based quantitative proteomic analysis of longissimus muscle from growing pigs with dietary supplementation of non-starch polysaccharide enzymes. J Zhejiang Univ Sci B. 2015;16(6):465-78.

\section{Publisher's Note}

Springer Nature remains neutral with regard to jurisdictional claims in published maps and institutional affiliations.
Ready to submit your research? Choose BMC and benefit from:

- fast, convenient online submission

- thorough peer review by experienced researchers in your field

- rapid publication on acceptance

- support for research data, including large and complex data types

- gold Open Access which fosters wider collaboration and increased citations

- maximum visibility for your research: over $100 \mathrm{M}$ website views per year

At BMC, research is always in progress.

Learn more biomedcentral.com/submissions 